\title{
Maturogenesis: A novel concept based on regeneration for peadatric patients
}

\author{
Kuldeep Singh 1,", Suneel Kumar Gupta ${ }^{2}$, Chanchal Singh ${ }^{3}$, Sakshi Kataria ${ }^{4}$ \\ 1,2Post Graduate, ${ }^{3}$ Professor \& HOD, ${ }^{4}$ Associate Professor, ${ }^{1-3}$ Dept. of Pedodontics and Preventive Dentistry, ${ }^{4}$ Public Health \\ Dentistry, ${ }^{1,2}$ KD Dental College \& Hospital, Mathura, Uttar Pradesh, NIMS Dental College \& Hospital, NIHMS University, \\ Jaipur, Rajasthan, ${ }^{4}$ Sudha Rustagi College of Dental Sciences \& Research, Faridabad, Haryana, India
}

*Corresponding Author:

Email: sakshikataria87@gmail.com

\begin{abstract}
The problems encountered while treating immature, necrotic teeth has led to a shift in the treatment protocol. The biologicallybased principles and regenerative endodontic protocols replacing the traditional methods. Preliminary research suggests that Revascularization has emerged as such an alternative. The stem and progenitor cells from the pulp and/or periodontium lead to root development. The aim of this paper is to accomplish a literature review concerning this novel concept.
\end{abstract}

Keywords: Maturogenesis, Regeneration, Immature Teeth, Revascularization, Revitalization.

\section{Introduction}

The last two decades have seen surplus increase in the clinical "tools" (i.e., materials, instruments, and medications). The knowledge, concepts from the trauma and tissue engineering fields has also revolutionized the treatment involving the dentin-pulp complex. $^{1}$

Conventionally, for immature teeth (incompletely developed apices) vital pulp therapy is the ultimate treatment of choice. Scientific evidence report that it is one of the most challenging situations for the practioner is through debridement of pulp canal space accompanied with increased possibility of root perforation and fractures around the cervical area. The open immature root apex does not let the apical seal of a root canal treatment resulting in subsequent failure.

Among children several other obstacle are seen: history of trauma, anatomical variations of the tooth such as dens invaginatus, and untreated dental caries, patient at prepubertal age is uncooperative. ${ }^{2}$ The walls of the root canal system are very fragile and thin in young patients, intensive biomechanical preparation cannot be achieved and the tooth remains weakened even after successful endodontic treatment. Difficulties are encountered while condensating the filling materials in the root canal system. Henceforth apical seal is also not achieved because of the widely open apical foramen. ${ }^{3}$ The success rate was quite low.

Kaiser, in the early 60 year proposed the clinical protocol utilizing calcium hydroxide $\mathrm{Ca}(\mathrm{OH})_{2}$ for the closure of apical seal. It was suggested to repeatedly change of $\mathrm{Ca}(\mathrm{OH})_{2}$ every 3 to 6 months as it will induce the formation of calcified tissue. This served as the gold standard treatment in such patients for a long time. ${ }^{3,4}$ The flexural strength was compromised making these teeth more prone to fractures.

Recently, a innovative bioactive material, Mineral Trioxide Aggregate (MTA) was introduced, by torabinejad and his colleagues with an aim to overcome the problems stated above. This new treatment shortened the treatment period and visits and to avoid increased fragility of the teeth. ${ }^{5}$ The major limitation of apexification which uses MTA is discontinuation of root development, making teeth susceptible to cervical root fractures.

In 2001, Iwaya published the very first case report which incorporated tissue engineering technique in the field of modern regenerative endodontic. These Regenerative endodontic procedures are biologically based primarily designed to repair or replace damaged tooth tissue structures, including dentin and root structure, including the cells of the pulp-dentin complex. The internal environment of the root system was modified so to produce a blood clot from which pulp regeneration will occur. Continued root development including apical closure and root thickening was made possible in the absence of true pulp regeneration by inducing environment that permits root maturation. Histological reports define it as a repair process rather than regeneration. ${ }^{6}$ Consequents reports have been published by Huang GT, Ghorbanzadeh A et al and Mustafa MM. ${ }^{7-9}$

This process explained above is known as Maturogenesis. It has been defined as physiologic root development, not restricted to the apical segment. The continued deposition of dentin occurs throughout the length of the root, providing greater strength and resistance to fracture.

However, there are still uncertainties regarding the correct terminology, and several different terms are used for these procedures. There is paucity of literature related to this concept especially in the field of pediatrics. Hence this review was attempted to throw light in this direction which would help the clinician to successfully manage the cases encountered in routine practice. ${ }^{1}$ 


\section{Regenerative endodontic: Terminologies}

Revascularization: Iwaya coined this term for the first time. ${ }^{10}$ This term was subsequently defended by claiming that the nature of the tissue inside the root system was not predictable. However, the term "revascularization" indicates the restoration of blood supply to the already damaged tissue. ${ }^{11}$

Revitalization: This term refers to the presence of nonspecific restoration of the vital tissue within the root system, without its relation to the formation of hard tissues and further development of the root. ${ }^{12}$

Regenerative endodontic procedure (REP): This term officially coined by the American Association of Endodontists (AAE), which includes therapies employing the principles of tissue engineering leading to the restoration of tissue resembling dental pulp. Unfortunately, even under sterile conditions in animal models, it was not possible to use the current protocol of maturogenesis to stimulate the regeneration of the dental pulp or similar tissue. ${ }^{13-16}$

Maturogenesis: This was firstly used with direct capping of the pulp of immature permanent teeth. It describes the physiological continued development of the entire root, and not only the apical segment. ${ }^{9,17}$

\section{Regenerative endodontic: Tissue engineering}

A multidisciplinary field combining engineering, medicine and biology with an aim to restore the function of damaged or completely destroyed tissues or organs. It is the knowledge of growth factors effecting broad range of cellular activities including migration, proliferation, differentiation and apoptosis of dental pulp as well as stem/progenitor cells. Its main components are: stem cells, tissue factors, and internal matrix. $^{18}$

1. Stem cells: The multipotent mesenchymal stem cells (MSC) play an important role in maturogenesis. Niches, small defined areas are present in them through which regulation occurs. These niches are seen mostly perivascularily ${ }^{(19)}$ and have three basic features.. ${ }^{20,}{ }^{21} \mathrm{An}$ anatomical area, is formed where these stem cells are regulated. It also affect the stem cells mobility. These stem cells are maintained in a quiet mode, when necessary, their differentiation is induced and their regenerative capacity is set in. Stem cells do survive under certain environmental conditions in the root canal system. They may also be actively transported to the root system by blood, or they may be attracted by tissue factors on the "cell homing" principle.

a. Stem cells of apical papilla (SCAP): The most important role in maturogenesis is played by these cells. These are basically the precursors of radicular pulp, which are less differentiated $^{22,23}$ and primary odontoblasts involved in the formation of radicular dentin. It is probably due to the proximity of the apical papilla to the apex that much higher concentrations of mesenchymal stem cells occur in blood from periapical region than in the bloodstream. ${ }^{24}$

b. Dental pulp stem cells (DPSC): Their role in maturogenesis is assumed when necrosis extends coronoapically. There have been cases reporting that apical residual pulp was probably present in an immature tooth with an extensive periapical finding. ${ }^{25,26}$ It was also shown that the DPSC were present unchanged in teeth with irreversible pulpitis..$^{27,28}$

c. Periodontal ligament stem cells (PDLSC): The ability of these cells to form calcified tissues is significantly lower compared to the above mentioned cells. ${ }^{29,30}$

d. Inflammatory periapical stem cells (iPAPSC): These are stem cells around the periapical granulomas or periapical cysts. ${ }^{31,32}$ It is unlikely that these stem cell lines could play a big role in maturogenesis.

e. Bone marrow stem cells (BMSC): These are very heterogeneous, well-researched mesenchymal stem cells, with limited role in maturogenesis.

2. Growth Factors: Tissue factors encased in the collagen matrix of dentin during dentinogenesis play a mojor role in maturogenesis. They modulating cell behaviour by acting as signalling molecules. They mediate intracellular communication. They are polypeptides or proteins that bind to specific receptors on the surface of target cells and act locally on target cells. Recent work enlist the following growth factors (Table 1):

Table 1: Growth factors in regenrative endodontics

\begin{tabular}{|r|l|}
\hline S No. & \multicolumn{1}{|c|}{ Growth factors } \\
\hline 1. & $\begin{array}{l}\text { Cytokines- initiate a cascade of intracellular signalling and acting in either } \\
\text { autocrine or paracrine manner. }{ }^{32,33}\end{array}$ \\
\hline 2. & $\begin{array}{l}\text { Platelet-Derived Growth Factor (PDGF): It is released by platelets, and } \\
\text { has potency in promoting angiogenesis and cell proliferation. }\end{array}$ \\
\hline 3. & $\begin{array}{l}\text { Transforming growth factor- } \beta \text { (TGF } \beta \text { ): They monitor cellular activities, } \\
\text { such as cell proliferation, cell differentiation, cell migration and } \\
\text { extracellular matrix synthesis, cell proliferation and production of the } \\
\text { extracellular matrix in dental pulp tissue culture are regulated by this, and }\end{array}$ \\
\hline
\end{tabular}




\begin{tabular}{|r|l|}
\hline & promotes odontoblastic differentiation of dental pulp cells. ${ }^{35,36}$ \\
\hline 4. & $\begin{array}{l}\text { Vascular Endothelial Growth Factor (VEGF): It is a heparin-binding } \\
\text { protein and functions are proliferation of endothelial cells and their } \\
\text { enhanced survival, stimulating neovascularization in the area of injury. }{ }^{39}\end{array}$ \\
\hline 5. & $\begin{array}{l}\text { Bone Morphogenetic Protein (BMP): It is subgroup of the TGF3. This } \\
\text { super family is involved in biological activities such as cell proliferation, } \\
\text { differentiation, and apoptosis. They have very strong osteoinductive and } \\
\text { chondrogenic effects, inducing mineralization. }{ }^{37,38}\end{array}$ \\
\hline 6. & $\begin{array}{l}\text { Fibroblast Growth Factor (FGF): During embryonic development and } \\
\text { wound healing, They plays key roles in cell migration, proliferation and } \\
\text { differentiation. It also regulates tooth morphogenesis by controlling cell } \\
\text { proliferation and differentiation. It is a potent angiogenic factor } \\
\text { stimulating new blood vessel formation in the dental pulp, along with } \\
\text { PDGF, and VEGF. }{ }^{40}\end{array}$ \\
\hline 7. & $\begin{array}{l}\text { Insulin-like Growth Factor (IGF): They are single chain polypeptides. } \\
\text { Their sequence is similar to proinsulin. They contribute in odontogenesis } \\
\text { and dental tissue repair through cell proliferation and differentiation. }{ }^{41}\end{array}$ \\
\hline 8. & $\begin{array}{l}\text { Nerve Growth Factor (NGF)/ Neutrophins: They promote the survival and } \\
\text { maintenance of sympathetic and sensory neurons. They also induce the } \\
\text { differentiation of immortalized dental papilla cells into odontoblasts. It } \\
\text { acts as a stimulant for mineralization. }{ }^{22}\end{array}$ \\
\hline 9. & $\begin{array}{l}\text { Dental Pulp/Dentin Regeneration by Cell Homing: A recent study reported } \\
\text { cell homing approach. The regenerate of the pulp-dentin complex occurs } \\
\text { by the delivery of growth factors rather than cells in entire human teeth } \\
\text { following root canal treatment. Various growth factors, including NGF, } \\
\text { PDGF, bFGF, VEGF and BMP7 were delivered singularly or in } \\
\text { combination into root canal spaces of endodontically treated human teeth } \\
\text { (without gutta percha filling).43 }\end{array}$ \\
\hline
\end{tabular}

\section{Internal matrix: Scaffold}

In tissue engineering, seeding of cells on scaffolds is known as 'creating a tissue construct'. This is essential to promote the formation of higher order tissue structures on which bioactive molecules called growth factors are embedded.

A 3D, physico-chemical-biological microenvironment is established at a local site where the framework for cell growth, differentiation and organization takes place. It should be porous so as to allow for placement of cells, biocompatible with host tissue and biodegradable so that it can be easily replaced by regenerative tissue. ${ }^{18}$ It should also allow for transportation of nutrients and waste and removal of waste products. ${ }^{44}$ It can be natural (collagen, dentin, fibrin, silk, alginate), and degraded enzymatically or synthetic (various polymers like PLA, PGA, etc.) and degraded by simple hydrolysis respectively. ${ }^{45}$

The blood clot formed after the stimulation of bleeding in the periapical area was used as scaffold on a wide scale for many years. However some studies have also reported PRGF as an alternative to the blood clot scaffold. In vivo tests on dogs were done to examine the quality of the resulting tissue using blood clot or PRGF, no difference was found between these two matrices in terms of success of the apical closure, the amount of the newly formed tissue and its quality. ${ }^{46-48}$
As the tissue-engineered pulp is not required to provide any structural support to the tooth. Therefore this tissue can be administered in a soft threedimensional scaffold matrix framework. A polymer hydrogel, having similar physical properties to that of living tissue: high water content, soft and rubbery consistency and low interfacial tension with water or biological fluids was injected at the site (injectable scaffold delivery). This Research focused on making hydrogels photo-polymerizable or self-hardening e.g., silanized hydroxyl-propyl-methyl cellulose, so that they form rigid structures once they are implanted into the tissue sites. ${ }^{49}$

Another injectable scaffold under research is: tricalcium phosphate. $\beta$-tricalcium phosphate. This is an alginate in gel phase and forms beads in solid phase. Treated dentin matrix also provides suitable environment for regeneration of dental tissue. Silk scaffolds are being used for mineralized osteo-dentin formation. The size and shape of silk scaffold pores guide mineralized tissue. A new material Enamel matrix derivatives (Emdogain) with amelogenins as a major component have also been used as potential scaffolds. ${ }^{49,50}$ 


\section{Clinical Protocol}

On the recommendations of the AAE, Regenerative endodontics committee in 2006 was establishes suggesting a workflow. In April 2015, the latest version was regarding the concentration of irrigating solutions and medications within the root canal. This standard protocol recommended two visits therapy, although successful case studies have been reported with onevisit therapies only. ${ }^{51}$

The general indications and contraindications for maturogenesis fall in line to the indications and contraindications for endodontic treatment.

\section{Absolute indications}

1. Tooth development status and diagnosis

2. The choice for permanent immature necrotic teeth where repeated access to the root system can be achieved.

\section{Relative indications}

1. Cvek classification:

Stage 1 to stage 3: When the Root is in early stage of development In later stages of Stage 4 and stage: MTA apexification is more favourable.

\section{Absolute contraindications}

1. Any history of allergy to antibiotics used in the TAP / DAP

2. Tooth destruction.

\section{First Visit}

a. Local anesthesia application is done, rubber dam placed and access cavity prepared.

b. The working length is determined with help of an apex locator and verification done using a measuring radiograph

c. Rinsing the canal with $20 \mathrm{ml}$ of $1.5 \% \mathrm{NaOCl}$ solution for five minutes.

d. The tip of the irrigating cannula should be introduced approximately $1 \mathrm{~mm}$ from the end of the root canal to minimize the cytotoxic effect on the apical tissues.

e. Subsequently, $20 \mathrm{ml}$ of saline solution is flushed in the canal for five minutes.

f. Paper points are used to dry the canal.

g. Medication is introduced into the canal

h. Firstly, $\mathrm{Ca}(\mathrm{OH})_{2}$ is applied via a cannula into the coronal third of the root or secondly, The antibiotic mixture is administered via a cannula $(20 \mathrm{G}$ diameter) $2 \mathrm{~mm}$ from the end of the root canal .

i. The other end of a paper point, can be used to achieve the condensation

j. Temporary closure. It is necessary to apply a sterile spacer, usually in the form of a Teflon tape. Application of a 3-4 mm thick GIC is subsequently recommended, or a sandwich-type filling material using calcium sulfate material and an adhesively fixed flow composite

\section{Second Visit}

a. The second visit is sechduled 1-4 weeks after the first visit. There should be an absence of clinical symptoms.

b. If not, repeat the first visit.

c. Local anesthesia without epinephrine (3\% mepivacaine) is used and use a rubber dam applied.

d. Removing the temporary fillings and repeated lavage with $30 \mathrm{ml}$ of EDTA solution for 10 minutes.

e. Drying with sterile paper points.

f. Creating a suitable environment in the root system, using one of the two possible techniques: Induction of bleeding and clot stabilization.

The care needs to be taken so that the Hertwig's epithelial sheath is not damaged during the induction of bleeding, as it plays a pivotal role in the further development of the root. The use of sterile K-file instruments of size ISO 20-25 is recommended, which should be pre-curved by about $30^{\circ}$ in order to induce greater irritation of the apical tissues and substantial bleeding. This instrument is to be inserted $2 \mathrm{~mm}$ beyond the physiological apical foramen and then rotated. As there is rich blood supply to the apical papilla, bleeding immediately occurs. The opposite end of a sterile paper point is soaked in physiological saline and attempt is made to stabilize the clot at roughly the level of CEJ. After about 15 minutes, the coagulum achieves stability. ${ }^{52}$

1. Application of collagen foam to the unstable clot at roughly the level of CEJ can also subsequently acts as matrix for the application of MTA.

2. Application of PRGF: PRGF is administered via a cannula into the root system. PRGF is fully stable after 5 minutes.

3. Application of MTA. MTA should be applied coronally at about the level of CEJ. In frontal region it is recommended to place the MTA rather below the CEJ because of the possibility of discoloration.

4. Another possibility is to use a nonstaining alternative to MTA, such as calcium silicate materials also known as bioceramics- the second generation (e.g. Biodentin, SEPTODONT, France) or third generation (e.g. BC RRM Fast Set Putty, Brasseler, Canada).

5. Completion of $3-4 \mathrm{~mm}$ thick layers using GIC or adhesive filling.

\section{Evaluation of Success of the Therapy}

1. If there is no pain and the tooth is clinically asymptomatic, therapy is a success.

2. Control radiographs made $3,6,9,12,18$, and 24 months after the therapy and then at yearly intervals for as long as 5 years. 
Primary goal: The reduction or loss of periapical translucency radiographically.

Secondary goal: Increase in the thickness of the root wall and the root length and the degree of closure of the apical region.

Tertiary goal: Restoration the function of the pulp, particularly the sensitive and immunologic function.

If the tooth is clinically calm after maturation, it is recommended not to carry out subsequent endodontic treatment. This is based on the recommendations for treatment of teeth with a calcified or obliterated root system after trauma

\section{Discussion}

A new promising treatment for non-vital immature teeth with a wide, open and blunderbuss apex is Revascularization or maturogenesis. It re-establishes the repair, vitality and regeneration of tissues resulting in further growth of the underdeveloped root and leading to thickening of fragile dentin walls. The primary requisite of this therapy is to create an aseptic environment so that in-growth of new tissues can take place inside the root canal space further leading to completion of root development and periapical closure. The usage of tri-antibacterial paste consisting of ciprofloxacin, metronidazole and minocycline is very effective in disinfection of the canal. The kill the bacteria present in the deep layers of root canal dentin and also effective against all types of pathogens which cause endodontic failures. ${ }^{53,54}$ These triple antibiotic paste does cause crown discoloration which can be minimized by placing the paste one $\mathrm{mm}$ below the CEJ of the tooth as reported in literature by various authors. ${ }^{55,56}$ Authors have suggested that sealing of dentinal tubules within the chamber can be done to decrease the intensity of discoloration. ${ }^{57,58}$

Research shows that three crucial components essential for the successful outcome of this procedure are firstly the stem cells which help in differentiation and supports the root development. An abundant number of undifferentiated mesenchymal cells into the pulp space are generated. These progenitor cells might play an essential role in regeneration of pulpal tissues. Secondly the growth factors which induce cellular proliferation and differentiation and third and last component is the physical matrix or scaffold which initiate differentiation and growth of new cells as an empty canal will not lead to in-growth of tissues from the periapical area. Thirdly, the scaffolds which can be of natural blood clot, collagen and Platelet-Rich-Plasma for the revascularization process. They provide structural and biological supports for cellular activities. $^{59,60}$

The traditional method to obtain fresh blood clot is extremely difficult and painful especially in pediatric patients. Also the maintenance of blood clot within the canal and placement of MTA over this blood clot technically becomes a difficult procedure. Also the condensation of MTA results in apical displacement of the material. ${ }^{5,13,14,15,17}$

These lead to introduction of a new biologically based scaffold matrix i.e. PRF. It is a PRF; an autologous healing biomaterial contains platelets, leukocytes, growth factors and key healing proteins (cytokines) in a dense fibrin matrix. It causes proliferation of human dental pulp cells and increase in protein synthesis and alkaline phosphatase activity. The human dental pulp cells present in the apical papilla remain vital and might differentiate into odontoblasts like cells under the influence of hertwig's epithelial root sheath (HERS) thereby enhancing the development of both hard and new tissue within the empty canal space. Although it is a difficult to handle due to its jelly consistency and requires specialized equipment for it's processing. $8,9,11$

To summarize, Revascularization procedures are appropriate treatment which promote maturogenesis, as well as bony healing. Several case reports on endodontic regeneration have used varying treatment protocols. The materials used for scaffold are accompanied by several advantages and disadvantages which need to be explored in consequent researches so that they can be utilised to their maximum potential. Human histological studies are the need of the hour essential to evaluate whether the revascularization procedure truly replicate the pulp-dentin complex. Clinical trials are also required to assess the overall outcomes of the procedure. $23,24,44,52$

\section{Conclusion}

This treatment does gives favorable results when followed strictly for treatment of immature permanent teeth with necrotic dental pulp is very demanding due to weak cooperation of the patient and the. As it is very sensitive and has to be followed strictly. It does bring significant thickening of the root wall as compared to other treatment modalities. The complete recovery of the pulpodentinal tissue in the real sense is not achieved yet it is assumed that the reparative apposition of hard tissues on the inner surface of the tooth improves its mechanical properties, especially with an early stage of root development. Several limitations are encountered with this therapy are: Discoloration, the time required for disinfection of the root canal space with triple antibiotic paste or calcium hydroxide and increased number of clinical sessions, Poor Root Development, insufficient bleeding, Root Canal Calcification/Obliteration, the need for a highly skilled treating dentist which needs to be explored in further researches.

\section{Acknowledgement: Nil}

Funding: No funding sources.

Conflict of interest: None declared. 


\section{References}

1. Hargreaves KM, Giesler T, Henry M, Wang Y. Regeneration potential of the young permanent tooth: what does the future hold?. Pediatr Dent 2008;30(3):25360 .

2. Cvek M.Prognosis of luxated nonvital maxillary incisors treated with calcium hydroxide and filled with guttapercha. A retrospective study. Endod Dent Traumatol 1992;8(2):45-55.

3. Fong Cheng D, Davis Martin J. Partial pulpotomy for immature permanent teeth, its present and future. Pediatr Dent 2002;24:29-32.

4. Anthony DR, Senia SE. The use of calcium hydroxide as a temporarypaste fill. Tex Dent J 1981:6-10.

5. Torabinejad M, Hong CU Mcdonald F, Pitt Ford TR. Chemical and physical properties of mineral trioxide aggregate. J Endo 1995;21:349-53.

6. Ghorbanzadeh A, Ghorbanzadeh A. Maturogenesis of Two Maxillary Central Incisors: A Case Report with 10 Years of Follow Up. J Dent (Tehran, Iran). 2015;12(4):306.

7. Mustafa MM. Maturogenesis and Osseous Healing of a Necrotic Immature Premolar using Revascularization Procedure-A Case Report and Review of Literature. Ann Med Health Sci Res 2018;8(2).

8. Weisleder R, Benitez CR. Maturogenesis: is it a new concept?. J Endod 2003;29(11):776-8.

9. Huang GT. A paradigm shift in endodontic management of immature teeth: conservation of stem cells for regeneration. J Dent 2008;36(6):379-86.

10. H.J. Kaiser, Management of wide open apex canals with calcium hydroxide, 21st Annual Meeting of the American Association of Endodontists, Washington DC, 17. 4. 1964

11. M. Trope, Regenerative potential of dental pulp, J Endod 2008;34(7):13-7.

12. G.T. Huang, and L.M. Lin, Letter to editor: comments on the use of term revascularization to describe root regeneration. J Endod 2008;34(5):511.

13. R. Lenzi, and M. Trope, Revitalization procedures in two traumatized incisors with different biological outcomes. $J$ Endod 2012;38(3):411-14.

14. .B. Thibodeau, F. Teixeira, M. Yamauchi, D.J. Caplan, and M. Trope, Pulp revascularization of immature dog teeth with apical periodontitis, J Endod 2007;33(6):680 89.

15. L.A. da Silva, P. Nelson-Filho, and R.A. da Silva et al., Revascularization and periapical repair after endodontic treatment using apical negative pressure irrigation versus conventional irrigation plus triantibiotic intracanal dressing in dogs' teeth with apical periodontitis. Oral Surg Oral Med Oral Pathol Oral Radiol Endod 2010;109(5):779-87.

16. N. Yamauchi, H. Nagaoka, S. Yamauchi, F.B. Teixeira, P. Miguez, and M. Yamauchi, Immunohistological characterization of newly formed tissues after regenerative procedure in immature dog teeth, $J$ Endod 2011;37(12): 1636-41.

17. W. Zhu, X. Zhu, G.T. Huang, G.S. Cheung, W.L. Dissayaka, and C. Zhang, Regeneration of dental pulp tissue in immature teeth with apical periodontitis using platelet-rich plasma and dental pulp cells. Int Endod J 2013;46(10):962-70.

18. M. Nakashima, and A. Akamine, The application of tissue engineering to regeneration of pulp and dentin in endodontics. J Endod 2005;31(10):711-18.

19. Ema H, Suda T. Two anatomically distinct niches regulate stem cell activity. Blood
20. Huang GT, Sonoyama W, Liu Y, Liu H, Wang S, Shi S. The hidden treasure in apical papilla: the potential role in pulp/dentin regeneration and bioroot engineering. $J$ Endod 2008;34(6):645-51.

21. Dimitrova-Nakov S, Baudry A, Harichane Y, Kellermann $\mathrm{O}$, Goldberg M. Pulp stem cells: implication in reparative dentin formation. J Endod 2014;40(4):S13-8.

22. Lenzi R, Trope M. Revitalization procedures in two traumatized incisors with different biological outcomes. $J$ Endod 2012;38(3):411-4.

23. Rodríguez-Lozano FJ, Bueno C, Insausti CL, Meseguer L, Ramirez MC, Blanquer M, Marin N, Martínez S, Moraleda JM. Mesenchymal stem cells derived from dental tissues. Int Endod J 2011;44(9):800-6.

24. Friedlander LT, Cullinan MP, Love RM. Dental stem cells and their potential role in apexogenesis and apexification. Int Endod J 2009;42(11):955-62.

25. Banchs F, Trope M. Revascularization of immature permanent teeth with apical periodontitis: new treatment protocol?. J Endod 2004;30(4):196-200.

26. Jung IY, Lee SJ, Hargreaves KM. Biologically based treatment of immature permanent teeth with pulpal necrosis: a case series. J Endod 2008;34(7):876-87.

27. Wang J, Wei X, Ling J, Huang Y, Gong Q. Side population increase after simulated transient ischemia in human dental pulp cell. J Endod 2010;36(3):453-8.

28. Pereira LO, Rubini MR, Silva JR, Oliveira DM, Silva IC, Poças-Fonseca MJ, Azevedo RB. Comparison of stem cell properties of cells isolated from normal and inflamed dental pulps. Int Endod J 2012;45(12):1080-90.

29. Lindroos B, Mäenpää K, Ylikomi T, Oja H, Suuronen R, Miettinen S. Characterisation of human dental stem cells and buccal mucosa fibroblasts. Biochem Biophys Res Comm 2008;368(2):329-35.

30. Liao J, Al Shahrani M, Al-Habib M, Tanaka T, Huang GT. Cells isolated from inflamed periapical tissue express mesenchymal stem cell markers and are highly osteogenic. J Endod 2011;37(9):1217-24.

31. J. Dokic, S. Tomic, and S. Cerovic et al., Characterization and immunosuppressive properties of mesenchymal stem cells from periapical lesions, $J$ Clin Peidontol 2012;39(9):807-16.

32. Marrelli M, Paduano F, Tatullo M. Cells isolated from human periapical cysts express mesenchymal stem celllike properties. Int J Biolog Sci 2013;9(10):1070.

33. Lind M. Growth factors: possible new clinical tools. A review. Acta Orthop Scand 1996;67(4):407-17.

34. Deuel TF, Senior RM, Huang JS, et al. Chemotaxis of monocytes and neutrophils to plateletderived growth factor. J Clin Invest 1982;69(4):1046-9.

35. Alvarez RH, Kantarjian HM, Cortes JE. Biology of platelet-derived growth factor and its involvement in disease. Mayo Clin Proc 2006;81(9):1241-57.

36. Watabe T, Miyazono K. Roles of TGF-beta family signaling in stem cell renewal and differentiation. Cell Res 2009;19(1):103-15.

37. He H, Yu J, Liu Y, et al. Effects of FGF2 and TGFbeta1 on the differentiation of human dental pulp stem cells in vitro. Cell Biol lnt 2008;32(7):827-34.

38. Saito T, Ogawa M, Hata Y, et al. Acceleration effect of human recombinant bone morphogenetic protein-2 on differentiation of human pulp cells into odontoblasts. $J$ Endod 2004;30(4):205-8.

39. Chen S, Gluhak-Heinrich J, Martinez M, et al. Bone morphogenetic protein 2 mediates dentin sialophosphoprotein expression and odontoblast differentiation via NF-Y signaling. J Biol Chem2008;283(28):19359-70. 
40. Mullane EM, Dong Z, Sedgley CM, et al. Effects of VEGF and FGF2 on the revascularization of severed human dental pulps. J Dent Res 2008;87(12):1144-8

41. Tran-Hung L, Mathieu S, About I. Role of human pulp fibroblasts in angiogenesis. J Dent Res. 2006; 85(9):81923.

42. Joseph BK, Savage NW, Young WG, et al. Expression and regulation of insulin-like growth factor-I in the rat incisor. Growth Factors 1993;8(4):267-75.

43. Arany S, Koyota S, Sugiyama T. Nerve growth factor promotes differentiation of odontoblast-like cells. J Cell Biochem 2009;106(4):539-45.

44. Kim JY, Xin X, Moioli EK, et al. Regeneration of dentalpulp-like tissue by chemotaxis-induced cell homing. Tissue Eng Part A 2010;16(10):3023-31.

45. Hargreaves KM, Giesler T, Henry M, Wang Y. Regeneration potential of the young permanent tooth: what does the future hold?. Pediatr Dent 2008;30(3):25360.

46. Zhang DD, Chen X, Bao ZF, Chen M, Ding ZJ, Zhong M. Histologic comparison between platelet-rich plasma and blood clot in regenerative endodontic treatment: an animal study. J Endod 2014;40(9):1388-93.

47. Jadhav GR, Shah N, Logani A. Comparative outcome of revascularization in bilateral, non-vital, immature maxillary anterior teeth supplemented with or without platelet rich plasma: A case series. J Conservative Dent 2013;16(6):568.

48. Huang GT. A paradigm shift in endodontic management of immature teeth: conservation of stem cells for regeneration. J Dent 2008;36(6):379-86.

49. Solomon RV, Faizuddin U, Guniganti SS, Waghray S. Analysis of the rate of maturogenesis of a traumatized Cvek's stage 3 anterior tooth treated with platelet-rich fibrin as a regenerative tool using three-dimensional cone-beam computed tomography: an original case report. Indian J Dent Res 2015;26(1):90.

50. Gathani KM, Raghavendra SS. Scaffolds in regenerative endodontics: A review. Dent Res J 2016;13(5):379

51. Thomson A, Kahler B. Regenerative endodonticsbiologically-based treatment for immature permanent teeth: a case report and review of the literature. Aus Dent J 2010;55(4):446-52.

52. Lee BN, Moon JW, Chang HS, Hwang IN, Oh WM, Hwang YC. A review of the regenerative endodontic treatment procedure. Restorative Dent Endod 2015;40(3):179-87.
53. Diogenes A, Henry MA, Teixeira FB, Hargreaves KM. An update on clinical regenerative endodontics. Endod Topics 2013;28(1):2-3.

54. Hoshino E, Kurihara-Ando N, Sato I, et al. In-vitro antibacterial susceptibility of bacteria taken from infected root dentine to a mixture of ciprofloxacin, metronidazole and minocycline. Int Endod J 1996;29:125-30.

55. Sato I, Ando-Kurihara N, Kota K, Iwaku M, Hoshino E. Sterilization of infected root-canal dentine by topical application of a mixture of ciprofloxacin, metronidazole and minocycline in situ. Int Endod J 1996;29:118-24.

56. Kim JH, Kim Y, Shin SJ, Park JW, Jung IU. Tooth discoloration of immature permanent incisor associated with triple antibiotic therapy: A case report. $J$ Endod 2010;36:1086-91.

57. Petrino JA, Boda KK, Shambarger S, Bowles WR, McClanahan SB. Challenges in regenerative endodontics: A case series. $J$ Endod 2010;36:536-41.

58. Reynolds K, Johnson JD, Cohenca N. Pulp revascularization of necrotic bilateral bicuspids using a modified novel technique to eliminate potential coronal discoloration: a case report. Int Endod J 2009;42:84-92.

59. Lovelace EA. Evaluation of the delivery of mesenchymal stem cells into the root canal space of necrotic immature teeth after clinical regenerative endodontic procedure. $J$ Endod 2011;37:133-38.

60. Hargreaves KM, Diogenes A, Teixeira FB. Treatment options: Biological basis of regenerative endodontic procedures. Pediatr Dent 2013;35:129-40.

61. Martin G, Ricucci D, Gibbs JL, Lin LM. Histological findings of revascularized/revitalized immature permanent molar with apical periodontitis using plateletrich plasma. $J$ Endod 2013;39(1):138-44.

62. Lin LM, Shimizu E, Gibbs JL, Loghin S, Ricucci D. Histologic and histobacteriologic observations of failed revascularization/ revitalization therapy: a case report. $J$ Endod 2014;40(2):291-95.

63. Khoshkhounejad M, Shokouhinejad N, Pirmoazen S. Regenerative endodontic treatment: report of two cases with different clinical management and outcomes. J Dent (Tehran) 2015;12(6):460-68.

How to cite the article: Singh K., Gupta S., Singh C., Kataria S. Maturogenesis: A novel concept based on regeneration for peadatric patients. IP Indian J Conserv Endod 2018;3(3):75-81. 